\title{
The Connotation and Logical Construction of Government Digital Transformation -- Based on the Analysis of Sociotechnical System Theory
}

\author{
Tian-peng Gao ${ }^{1, a}$, Hong $\mathrm{Su}^{1, \mathrm{~b}^{*}}$, and Ting $\mathrm{Yu}^{1, \mathrm{c}}$ \\ ${ }^{1}$ College of Public Administration, University of Electronic Science and Technology of China, Chengdu, Sichuan, China
}

\begin{abstract}
With the in-depth application of digital technology in government governance toward integration and in-depth development, government digital transformation has flourished in practice and research, which characterized by digitalization, networking and intelligentization, the digital transformation of government develops vigorously in practice and research. However, the current academic interpretation of the connotation and logic of the government's digital transformation is mostly from the perspective of empirical research, and lacks analysis of the theoretical logic behind it. Therefore, guided by the theory of sociotechnical system, this paper constructs the theoretical logic of government digital transformation on the basis of putting forward the research framework of general digital transformation, and points out that government digital transformation is the result of the intersection of government operation value and goal and general digital transformation logic, so as to enrich the theoretical connotation of government digital transformation.
\end{abstract}

\section{Introduction}

With the new round of technological revolution and industrial transformation, the new generation of information technology, represented by big data, cloud computing, artificial intelligence, Internet of Things and $5 \mathrm{G}$, is changing rapidly. They not only accelerate the integration and innovation of information technology and various fields and industries of society, but also promote the arrival of the digital economy era, which is interconnected, data-driven, and intelligence-led, the wave of digital transformation is coming. As the "top priority" of digital transformation, government digital transformation shows vigorous vitality and great development potential. It has become a common strategic choice for many countries to realize the modernization of government governance, improve the level of economic development, and enhance citizen participation and social innovation [1].

However, government digital transformation is deeply rooted in technology, innovation, culture, organizational practice and strategy, which leads scholars and organizations in different regions and fields to analyze government digital transformation from the empirical level rather than the theoretical logic. So, how should we understand the connotation and logic of government digital transformation from the theoretical perspective? Guided by the theory of sociotechnical systems, this article first builds a general digital transformation research framework, and then combines the value and goals of government operations to propose a logical framework for government digital transformation. What needs to be emphasized is that as an open proposition in the process of development, this paper does not strive to form a general definition with general consensus, but aims to break through the limitations of the current literature which focuses more on the practical level and relatively ignores the theoretical logic behind the government digital transformation, so as to provide theoretical support for the research and development of government digital transformation.

\section{CONSTRUCTING THE LOGIC OF GENERAL DIGITAL TRANSFORMATION}

Digital transformation is a systematic and huge project involving a series of changes in products, organizations, operations, customers and human resources, which requires us not only to analyze from the perspective of technology, but also to consider social factors such as organization, process, employees and culture. On the basis of introducing the background and connotation of sociotechnical system theory, this paper puts forward the logical framework of general digital transformation.

\subsection{Theoretical background: sociotechnical system theory}

The term "sociotechnical system" was proposed by Emery and Trist in the 1950s based on basic research on the British coal mining industry. The theory believes that an organization is a sociotechnical system formed by the

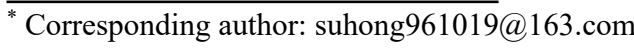


interaction of a social subsystem and a technological subsystem, that is, a compound and open system formed by various elements including formal organization, informal organization, member's quality, culture and so on [2].

The elements that constitute the sociotechnical system are interdependent and interact within the organization. Changes in the elements in one subsystem will lead to changes in the elements in the other subsystem. The performance of the whole system ultimately depends on the result of interaction and joint optimization between the social and technology subsystems under external influence [3], and finally reacts on the external environment (Figure 1). As a specific joint optimization method, this theory aims to design a system with open system characteristics to better deal with the complexity, dynamics, new technology and competition of the environment [4].

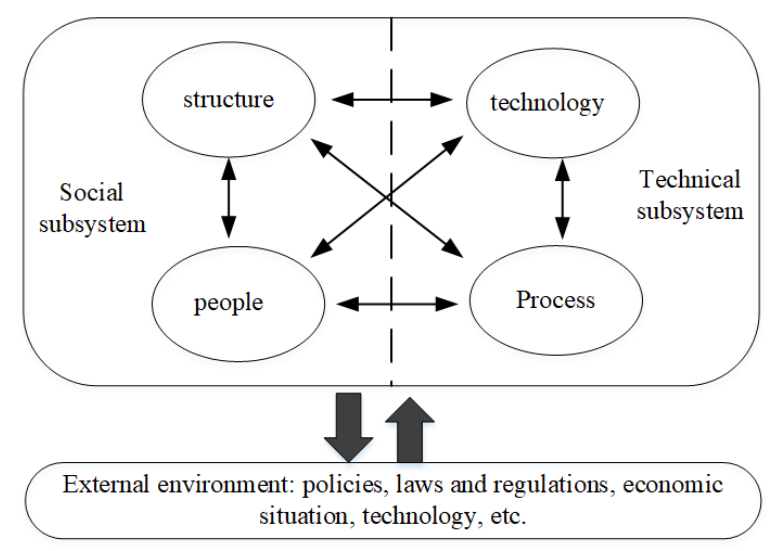

Fig. 1. Elements and interactions of sociotechnical system.

\subsection{Research framework: the logic of general digital transformation}

Industry, enterprise, government and other organizations, which are composed of technology, employees, organizational structure, culture, products or services and other elements, are deeply influenced by the external environment. They are all a complex and open sociotechnical systems. The digital transformation of organization is not only a technical problem, but also a process driven by technology subsystem and social subsystem. Based on this complexity, when designing and upgrading the system, decision makers should care about not only the management of the internal social system and technical system, but the adjustment of the external environment.

In the background of the digital age, as the most active factor in system, digital technology is not only an objective technical tool, but more importantly, a digital thinking mode of "interconnection of all things". Digital technology determines the way other factors participate in production and the results of participation, and also affects the distribution and consumption of products, as well as the relationship and interaction between social members. At the same time, the general digital transformation mainly focuses on the four capabilities of service, process, decision-making and data sharing, and the key influencing factors include institutional strategy, governance and organization, leadership, talent and culture, technology and so on [5]. Therefore, when studying digital transformation, while focusing on the key role of digital technology in digital transformation, we should also consider social factors such as services, talents, and culture to maintain the balance of the sociotechnical system. Accordingly, this article summarizes the logic of general digital transformation based on the theory of sociotechnical systems as follows:

The development of digital technologies such as big data, cloud computing, and artificial intelligence and the digital economy have stimulated business innovation and industrial transformation. Under the competitive pressure of peer organizations, starting from the needs of customers and users, the managers of organizations begin to examine the organizational structure with digital thinking, formulate digital strategic planning, integrate digital technology with the internal elements of the organization, so as to promote the all-round transformation of organizational structure, business process, operation mode and talent training. As a sociotechnical system, the principle of "Pull one hair and you move the whole body" makes the organization's structure, process, culture, technology, employees and other elements interact in the process of digital transformation, resulting in efficiency improvement, process reengineering, ecological construction and other positive effects, so as to promote the development of enterprises in the direction of service sharing, intelligent management, business digitization and organization platform Finally, it grows into a new type of intelligent organization in the process of continuous change. On the contrary, the transformation and innovation of the organization will also react on the external environment. The new smart organization can stimulate more social needs by updating the business model, stimulate the continuous iteration of the new generation of digital technology, and then promote the economic development and social progress.

\section{Constructing the connotation and logic of government digital transformation}

As a typical sociotechnical system, the government's digital transformation is also a dynamic process of internal social subsystems and technological subsystems under the influence of the external environment. It is the result of the intersection of the theoretical logic of digital transformation and the value and goals of government operations.

\subsection{The value and goals of government operations}

In a modernized country, the government, as an agent of people's power, has its basic function to design policies and use policy tools to implement and manage policy decisions. The government upholds the basic concept of serving society and citizens to pursue value such as 
democracy and the rule of law, openness, fairness, justice, and transparency. With the rapid development of technological innovation, the needs of citizens have become increasingly diversified. From the initial office automation to e-government to the current construction of digital government, its value pursuit and goals are constantly updated and changed. In addition to the above basic concepts, Table 1 lists the digital government strategy documents issued by major developed countries in the world and their related value pursuits and goals in order to find out the main value and goals of the current digital government construction and operation.

Table 1. The value and goals of government operations in major developed countries.

\begin{tabular}{|c|c|c|}
\hline $\begin{array}{l}\text { Country } \\
\text { (Year) }\end{array}$ & $\begin{array}{c}\text { Government } \\
\text { documents and } \\
\text { strategies }\end{array}$ & Value and Goals \\
\hline $\begin{array}{l}\text { The } \\
\text { United } \\
\text { States } \\
(2012)\end{array}$ & $\begin{array}{c}\text { Digital } \\
\text { Government: } \\
\text { Building a 21st } \\
\text { Century Platform } \\
\text { to Better Serve } \\
\text { the American } \\
\text { People } \\
\end{array}$ & $\begin{array}{l}\text { Build a public-centered } \\
\text { government and a } \\
\text { high-quality public } \\
\text { service platform for the } \\
21 \text { st century }\end{array}$ \\
\hline $\begin{array}{l}\text { South } \\
\text { Korea } \\
(2013)\end{array}$ & $\begin{array}{l}\text { "Government } \\
\text { 3.0" strategic } \\
\text { objectives }\end{array}$ & $\begin{array}{l}\text { Build a transparent, } \\
\text { capable and service- } \\
\text { oriented government }\end{array}$ \\
\hline $\begin{array}{c}\text { Singapore } \\
(2014)\end{array}$ & $\begin{array}{c}\text { Smart Nation } \\
2025\end{array}$ & $\begin{array}{l}\text { "Big data governance" } \\
\text { to provide quality and } \\
\text { convenient public } \\
\text { services to the public }\end{array}$ \\
\hline $\begin{array}{c}\text { Denmark } \\
(2016)\end{array}$ & $\begin{array}{c}\text { Digital Strategy } \\
2016-2020\end{array}$ & $\begin{array}{l}\text { Build a user-friendly, } \\
\text { simple and efficient } \\
\text { public sector }\end{array}$ \\
\hline $\begin{array}{l}\text { Britain } \\
(2017)\end{array}$ & $\begin{array}{c}\text { Government } \\
\text { transformation } \\
\text { strategy (2017- } \\
\text { 2020) }\end{array}$ & $\begin{array}{l}\text { Taking people's needs } \\
\text { as the core, improve } \\
\text { the efficiency of } \\
\text { government digital } \\
\text { services and improve } \\
\text { the relationship } \\
\text { between people and } \\
\text { government }\end{array}$ \\
\hline $\begin{array}{c}\text { Australia } \\
(2018)\end{array}$ & $\begin{array}{c}\text { "2025 } \\
\text { government } \\
\text { digital } \\
\text { transformation } \\
\text { strategy" }\end{array}$ & $\begin{array}{l}\text { With people's needs as } \\
\text { the core of the policy } \\
\text { and service design; } \\
\text { Ensure credible } \\
\text { policies and services } \\
\text { capricious; Provide the } \\
\text { value of public services }\end{array}$ \\
\hline
\end{tabular}

By browsing the content of the table, we can see that these words such as "public-centered", "high-quality public service", "scientific decision-making", "transparent service-oriented government" "friendly, concise and efficient public sector" "improving the public" "relationship with the government" "trustworthiness of policies and services" show that developed countries are mainly public-centric and demand-oriented when formulating digital government strategies in order to improve government governance and government services. They are committed to building an open, shared, efficient, collaborative, and clean digital government. According to the functions and ownership of the government, combined with the strategic value and goals of the above-mentioned national digital government, we summarize the value and goals of government operations as: Build a digital government that takes the public as the center and realizes scientific decision-making, efficient services, collaborative governance and intelligent supervision.

\subsection{The Connotation and Logic of Government Digital Transformation}

The government's digital transformation is the result of the combined effect of the general digital transformation theory and the government's operational value and goals. In theoretical logic, government digital transformation conforms to and belongs to the basic principles of digital transformation theory; in practical logic, government digital transformation is guided by the value and goals of government operations, showing different characteristics from other organizations' digital transformation. The specific transformation is shown in Figure 2.

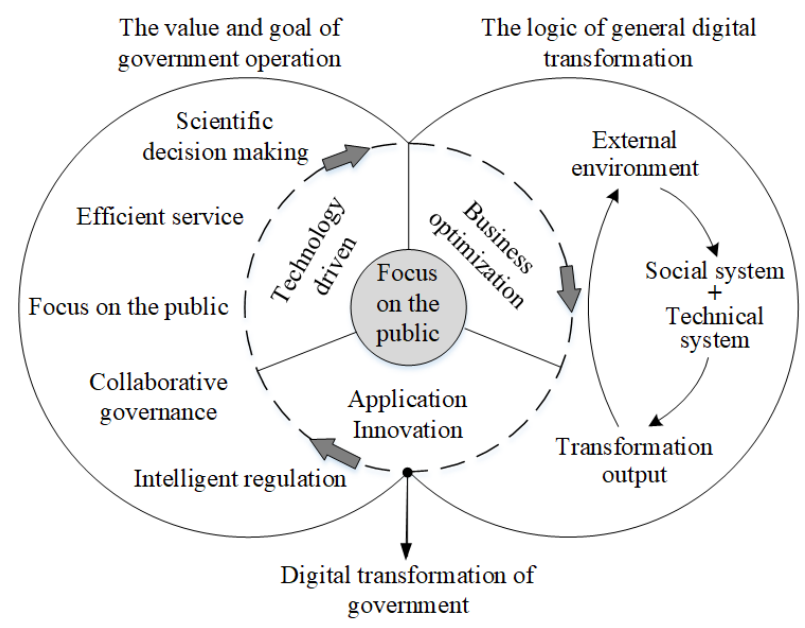

Fig. 2. The logic of the government's digital transformation.

On the one hand, the value and goals of government operations determine the basic value orientation of government digital transformation centered on the public. The characteristics of the data-driven and interconnected digital age determine the government's pursuit of scientific decision-making, efficient services, collaborative governance and intelligent supervision in the process of digital transformation. The digital transformation of government will produce new relationships and changes, involve participants and resources outside public organizations and change service values and concepts. But it will not change the nature and functions of the government. Therefore, different from the digital transformation of business organizations, the government's digital transformation is based on the needs of the public and aims to create more public value for society.

On the other hand, as a complex and open sociotechnical system composed of social subsystem and technical subsystem, the government's digital transformation follows the basic logic of general digital 
transformation. The digital transformation of government is not only the introduction of digital technology but also the change of multiple interconnected sociotechnical systems. Digital technology starts from changing the way of information collection, production, storage and dissemination then affects the way of interaction between organizations and individual in order to change the way of interaction between the government and the public finally [6]. The digital transformation of the government has caused the flow and interaction of elements such as the government's internal structure and processes which has greatly changed the government's governance model. Finally it realizes a more advanced and efficient digital government form. At the same time, the continuous development of digital government will in turn affect the external environment.

Specifically, big data analysis technology and methods enable the government to grasp social information comprehensively, timely and accurately, analyze social problems and social contradiction and make accurate and scientific decisions; the development of the Internet makes the services provided by the government move offline to online and provide users with customized and personalized services through a combination of online and offline methods to meet the diverse and precise needs of the public. The efficient openness and sharing of data allowing governments, enterprises, and the public to share data management applications breaks the traditional bureaucratic collaboration method of departments. This has transformed the government from the previous way of doing things to a service mechanism of active coordination and close cooperation. The openness of big data enhances the transparency of government operations. Big data supervision makes it possible to establish crossdepartmental and cross-regional linkage and collaboration mechanisms, which makes up for the shortcomings of traditional supervision and realizes intelligent supervision.

To sum up, this article believes that the logic of government digital transformation is to focus on the public and deeply integrate the new generation of information technology with internal government data, technology, personnel, processes, and services. To sum up, this article believes that the logic of government digital transformation is to focus on the public and deeply integrate the new generation of information technology with internal government data, technology, personnel, processes and services. This will cause the interaction and dynamic evolution of the internal elements of the government, make the government's business process, organizational structure and service platform digitally transformed, realize scientific decision-making, efficient service, collaborative governance and intelligent supervision and finally reach a more advanced state of government-digital government.

\section{Conclusion}

Based on the theoretical guidance of socio-technical theory, this paper believes that the digital transformation of government is the result of the combined effect of the general digital transformation theoretical logic and the value and goals of government operations. It not only conforms to and belongs to the basic principles of digital transformation theory but is also guided by the value and goals of government operations. And it presents different characteristics from other organizations' digital transformations. Therefore, in the process of digital transformation of the government, the government can only use data as the basis and digital technology as a means to actively transform its own sociotechnical system in order to make technology, organization, and social resources develop better and finally realize the goal of digital government as soon as possible.

\section{References}

1. Zhang Yanhua, Wang Liping. Research and Enlightenment on Digital Transformation Strategy of Foreign Governments. E-Government 215.11 (2020): 14-22.

2. Sociotechnical system, MBA think tank Encyclopedia (2015)

https://wiki.mbalib.com/wiki/\%E7\%A4\%BE\%E4\%BC\% 9A\%Е6\%8A $\% 80 \% \mathrm{E} 6 \%$ C $\%$ AF $\%$ E7\%B3\%BB $\%$ E7 $\% \mathrm{BB} \% 9 \mathrm{~F}$

3. Bakunzibake, Pierre, Gunnar O. Klein, and Sirajul M. Islam. E-government implementation process in Rwanda: Exploring changes in a sociotechnical perspective. Business Systems Research: International journal of the Society for Advancing Innovation and Research in Economy 10.1 (2019): 53-73.

4. Walker, Guy H., et al. A review of sociotechnical systems theory: a classic concept for new command and control paradigms." Theoretical issues in ergonomics science 9.6 (2008): 479-499.

5. Corydon, Bjarne, Vidhya Ganesan, and $\mathrm{M}$. Lundqvist. Digital by default: A guide to transforming government. New York: McKinsey \& Company (2016).

6. Ding Yu. The digital transformation of bureaucratic government and the relief of bureaucratic crisis. Journal of Nanjing University (Philosophy· Humanities SSocial Sciences) 57.06 (2019): 112-120. 